\title{
Dual-probe in Situ Hybridization
}

National Cancer Institute

\section{Source}

National Cancer Institute. Dual-probe in Situ Hybridization. NCI Thesaurus. Code C159521.

An in situ hybridization assay for HER2/Neu that uses probes for both HER2 and chromosome 17. 